\title{
Glucose Metabolism and Catecholamine Responses during Physical Exercise in Non-Insulin-Dependent Diabetes
}

\author{
Nevbahar Turgan ${ }^{1}$, Canan Çoker ${ }^{2}$, Füsun Hamulu ${ }^{3}$, Semra Elmaci ${ }^{4}$, Candeğer Yllmaz ${ }^{3}$, Biltan Ersöz ${ }^{1}$ and \\ Çetin İsleğen ${ }^{4}$ \\ 1 Department of Clinical Biochemistry \\ 2 Research Laboratory \\ ${ }^{3}$ Department of Endocrinology \\ 4 Department of Sports Medicine \\ Ege University School of Medicine, Bornova, İzmir, Turkey
}

Summary: Blood glucose, lactate, insulin, C-peptide, norepinephrine and epinephrine concentrations were determined in non-insulin-dependent diabetic patients and in healthy controls before, during and after moderate exercise, to evaluate the effects of physical exercise on glucoregulation. Ten diabetic and ten healthy control females bicycled 14 minutes at $60 \%$ of their maximal heart rates. In the diabetic patients, there were no significant changes in blood glucose levels post-exercise, while in controls the 60 minute post-exercise levels were higher than those measured in mid-exercise $(p<0.05)$. Lactate concentrations increased with exercise in both groups in a similar manner, with highest values at the end of exercise. No significant changes in insulin and C-peptide levels were induced with exercise in either group. Norepinephrine and epinephrine concentrations increased 2.5-3 fold with exercise in both groups ( $p<0.05$ for all values) but in the diabetics an earlier and prolonged catecholamine response was observed. We propose that catecholamines prevent hypoglycaemia during exercise when changes in insulin and C-peptide do not occur. In diabetic patients with good metabolic control, the glucoregulatory response to exercise is not worse than in anthropometrically similar controls with similar levels of fitness.

\section{Introduction}

The beneficial effects of exercise on glucose metabolism in diabetic patients has been under investigation for some considerable time. Evidence has been presented for improved insulin action during exercise in both insulin-dependent and non-insulin-dependent diabetic patients (1). Due to its additional beneficial effects on cardiorespiratory fitness, psychological well-being, blood lipid profile, adiposity and blood pressure, exercise training became an important component of the treatment of diabetic patients $(2,3)$. Most of the positive effects of exercise seem to benefit non-insulin-dependent diabetic patients through improved peripheral insulin sensitivity and enhanced insulin binding to receptor sites on the muscle cell, thus increasing muscle glucose uptake without changing insulin levels (4). At exercise intensities of $\sim 50-60 \%$ of $\mathrm{VO}_{2 \max }$ (moderate exercise), blood glucose concentrations remain stable in patients with diabetes that is under good metabolic control (5). In this situation, euglycaemia is usually maintained due to feedback signals from glucosensors sensitive to minute decrements in glycaemia elicited by the increase in peripheral glucose utilization. These signals also stimulate the secretion of counterregulatory hormones (cate-

cholamines, glucagon, cortisol and growth hormone) which exert insulin antagonistic effects. Among these, catecholamines (emergency hormones) rapidly influence glucose control by transiently increasing hepatic glucose production, inhibiting peripheral glucose utilization for several hours and supplying the liver with gluconeogenic substrates (lactate, pyruvate, alanine) (6). In addition to the insulin resistance caused by circulating catecholamines, the increased sympathetic activity of norepinephrine at the sympathetic nerve endings in the islets of Langerhans diminishes insulin release during exercise, thereby helping to maintain glucose homeostasis (7). In the skeletal muscle, epinephrine binds to $\beta$-adrenergic receptors on the membrane, activates phosphorylase a and initiates glycogen breakdown with a consequent increase in lactate production (8). Under basal conditions, the plasma content of norepinephrine is 3-4 times greater than that of epinephrine. This is attributed to the fact that norepinephrine, which is a major neurotransmitter of the sympathetic nervous system, is secreted into the circulation from the terminal nerve endings. Changes in plasma norepinephrine content during exercise reflect sympathetic nervous 
system activity. The major source of circulating epinephrine is the adrenal glands (chromaffin cells) which release catecholamines in response to sympathetic stimulation and other influences such as hypoxia or hypoglycaemia (9).

Most of the studies on exercise and glucoregulation have assessed the effects of intense exercise on diabetes (1013). Relatively little information is available regarding the regulation of glucose metabolism in non-insulin-dependent diabetic patients during short-term moderately intense exercise. Because individuals are being encouraged to perform moderate exercise based on the expectation that this will improve their glycaemic control, we attempted to assess the effects of moderately intense exercise on hormonal and metabolic responses, with special emphasis on catecholamines, during and after exercise in patients with non-insulin-dependent diabetes.

\section{Materials and Methods}

\section{Subjects and procedures}

Participants in the study were twenty women, ten with non-insulindependent diabetes and ten controls. Each had been informed of the nature and purpose of the study and gave consent as prescribed by the institutional human ethics committee. The mean age was $45.67 \pm 2.16( \pm$ SEM) years for the diabetic group and 39.17 \pm 1.83 for the control group. The mean duration of diabetes was $3.05 \pm 0.82$ years. All diabetics were treated with oral antidiabetic agents: second generation sulphonylurea gliclazide (maximum 80 $\mathrm{mg}, \mathrm{b} . \mathrm{i} . \mathrm{d}$.). There was no clinical evidence of macrovascular, microvascular or neurological complications of diabetes mellitus. All had normal exercise electrocardiograms. None participated in any regular fitness programme and their level of fitness ranged from poor to average. Anthropometric and exercise data are presented in table 1 .

\section{Protocol}

Two days before each study, the subjects exercised on a cycle ergometer during which heart rates, electrocardiograms, systolic and diastolic blood pressures were monitored. The level of exercise predicted to give $60 \%$ of maximal heart rate was determined and the corresponding $\mathrm{VO}_{2 \max }$ was estimated indirectly according to Astrans-Rhyming's nomogram. Weight (kg), height (m), body mass index $\left(\mathrm{kg} / \mathrm{m}^{2}\right)$, waist/hip ratio, skinfold thickness (biceps, triceps, subscapular, abdominal, quadriceps, $\mathrm{mm}$ ), \% body fat, indirect $\mathrm{VO}_{2 \max }$ and workload (watts) were recorded for all subjects. Exercise studies were performed in the morning in the fasting state and started after a minimum of 1 hour after a catheter with a three-way stopcock had been inserted in an antecubital vein. The vein was kept patent by heparin diluted 20 -fold with $9 \mathrm{~g} / \mathrm{l} \mathrm{NaCl}$. All subjects exercised at $60 \%$ of their maximal heart rates for a period of 14 minutes. Basal (rest), mid-exercise $(7 \mathrm{~min})$, end-exercise $(14 \mathrm{~min}$ ) heart rate, systolic and diastolic blood pressures were recorded. Electrocardiograms were recorded before, during and after exercise. Blood samples were drawn at rest, midpoint $(7 \mathrm{~min})$ of exercise, at the end of exercise (time 0 of recovery) and at 20 and 60 minutes of recovery.

\section{Analytical methods}

Serum glucose concentrations were determined by the glucose oxidase method on a Hitachi 704 analyser (intra-assay precision $2.1 \%$; inter-assay precision $3.2 \%$ ). Plasma lactate concentrations were determined by the kinetic method, using the UV kit from BoehringerMannheim, Germany (intra-assay precision $3.6 \%$; inter-assay precision $4.7 \%$ ). Serum insulin and C-peptide were determined by radioimmunoassay (insulin with the DPC Coat-A-Count RIA kit; C-peptide with the Diagnostic Systems Lab, RIA kit). Intra-assay precision was 4.4 and $5.7 \%$, inter-assay precision 5.1 and $7.8 \%$, for insulin and C-peptide, respectively.

Plasma norepinephrine and epinephrine concentrations were determined by high performance liquid chromatography (HPLC). The

Tab. 1 Subjects and exercise data (mean \pm SEM)

\begin{tabular}{|c|c|c|c|}
\hline & $\begin{array}{l}\text { Control } \\
(n=10)\end{array}$ & $\begin{array}{l}\text { Diabetics } \\
(n=10)\end{array}$ & $\mathbf{P}$ \\
\hline Age (a) & $39.17 \pm 1.83$ & $45.6 \pm 2.16$ & NS \\
\hline Height $(\mathrm{cm})$ & $157.33 \pm 3.05$ & $158.33 \pm 1.76$ & NS \\
\hline Weight (kg) & $74.45 \pm 4.53$ & $72.77 \pm 6.33$ & NS \\
\hline Body mass index $\left(\mathrm{kg} / \mathrm{m}^{2}\right)$ & $29.98 \pm 1.22$ & $28.83 \pm 1.97$ & NS \\
\hline Waist/hip ratio & $0.92 \pm 0.04$ & $0.94 \pm 0.01$ & NS \\
\hline Abdominal skinfold (mm) & $46.37 \pm 2.02$ & $44.77 \pm 3.26$ & NS \\
\hline Body fat (\%) & $27.08 \pm 1.28$ & $25.52 \pm 1.48$ & NS \\
\hline Indirect $\mathrm{VO}_{2 \max }(\mathrm{ml} / \mathrm{kg} \cdot \min )$ & $30.07 \pm 3.04$ & $25.35 \pm 1.37$ & NS \\
\hline Workload (watt) & $32.50 \pm 3.59$ & $34.17 \pm 5.07$ & NS \\
\hline $\begin{array}{l}\text { Heart rate }\left(\min ^{-1}\right) \\
\text { rest } \\
\text { mid-exercise }(7 \mathrm{~min}) \\
\text { end-exercise (recovery } 0) \\
\text { recovery- } 20 \text { min } \\
\text { recovery- } 60 \mathrm{~min}\end{array}$ & $\begin{aligned} 77.17 & \pm 2.96 \\
105.67 & \pm 5.01 \\
109.83 & \pm 5.77 \\
85.13 & \pm 2.66 \\
81.83 & \pm 2.64\end{aligned}$ & $\begin{array}{r}84.17 \pm 2.51 \\
104.5 \pm 1.38 \\
105.67 \pm 1.56 \\
89.00 \pm 2.03 \\
84.67 \pm 0.80\end{array}$ & $\begin{array}{l}\text { NS } \\
\text { NS } \\
\text { NS } \\
\text { NS } \\
\text { NS }\end{array}$ \\
\hline $\begin{array}{l}\text { Systolic blood pressure }(\mathrm{mm} \mathrm{Hg} \text { ) } \\
\text { rest } \\
\text { end-exercise }\end{array}$ & $\begin{array}{l}115.5 \pm 5.5 \\
123.3 \pm 5.6\end{array}$ & $\begin{array}{l}116.7 \pm 17.8 \\
120.1 \pm 6.3\end{array}$ & $\begin{array}{l}\text { NS } \\
\text { NS }\end{array}$ \\
\hline $\begin{array}{l}\text { Diastolic blood pressure (mm } \mathrm{Hg} \\
\text { rest } \\
\text { end-exercise }\end{array}$ & $\begin{array}{l}80.0 \pm 5.16 \\
83.3 \pm 4.8\end{array}$ & $\begin{array}{l}83.3 \pm 3.3 \\
88.3 \pm 2.8\end{array}$ & $\begin{array}{l}\text { NS } \\
\text { NS }\end{array}$ \\
\hline
\end{tabular}

NS: not significant 
HPLC system consisted of an electrochemical detector (Shimadzu LC-6A), a solvent delivery system (Shimadzu LC GAD), a Rheodyne Model 7125 injector with a loop of $100 \mathrm{ml}$. A glassy carbon working electrode was set at $650 \mathrm{mV}$ versus an $\mathrm{Ag} / \mathrm{AgCl}$ reference electrode. The sensitivity of the detector was maintained at $1.0 \mathrm{nA}$ full scale.

For sample pretreatment, the commonly used extraction procedure based on the selective adsorption on alumina at $\mathrm{pH} 8.6$, followed by elution with perchloric acid at a low $\mathrm{pH}$ between 1.0 and 2.0, was applied with technical modifications $(14,15)$. Internal standard $(100 \mu \mathrm{l})(1 \mathrm{~g} / \mathrm{l})$ dihydroxybenzylamine in 0.2 $\mathrm{mol} / 1 \mathrm{HClO}_{4}$ ) was added to $1 \mathrm{ml}$ of plasma; $30 \mathrm{mg}$ of acid washed alumina (WA-4) was added, followed by $5 \mathrm{~min}$ of vigorous shaking.

The $\mathrm{pH}$ of the solution was adjusted to above 8.0 with $1 \mathrm{ml}$ Tris buffer $\left(1 \mathrm{~mol} / /\right.$ Tris base $+20 \mathrm{mmol} / 1 \mathrm{Na}{ }_{2}$ EDTA $+10 \mathrm{mmol} / / \mathrm{so}$ dium metabisulphite; $\mathrm{pH}=8.6$ ). After shaking for another $10 \mathrm{~min}$ the sample was centrifuged for $10 \mathrm{~min}$ at $2000 \mathrm{~g}$ and $4^{\circ} \mathrm{C}$. The supernatant was discarded and the alumina was washed three times with $1 \mathrm{ml}$ cold water with brief centrifugation between washes. The catecholamines were extracted with $125 \mu \mathrm{l} 0.2 \mathrm{~mol} / 1 \mathrm{HClO}_{4}$ with vortex mixing for $5 \mathrm{~min}$ and final centrifugation for $10 \mathrm{~min}$ at $2000 \mathrm{~g} 4{ }^{\circ} \mathrm{C}$. Fifty $\mu \mathrm{l}$ of eluant was then injected into the HPLC column (100 mm $\times 4.6 \mathrm{~mm} \mathrm{C18}$ reverse phase column packed with $3 \mathrm{~mm}$ particles of Alltech Adsorbosphere). The mobile phase consisted of $0.025 \mathrm{~mol} / \mathrm{l}$ citric acid, $0.025 \mathrm{~mol} / 1 \mathrm{NaH}_{2} \mathrm{PO}_{4}, 0.005$ $\mathrm{mol} / 1 \mathrm{Na}_{2} \mathrm{EDTA}, 34 \mathrm{mg} / \mathrm{l}$ octane sulphonic acid (Na salt), $\mathrm{pH}$ was adjusted to 3.4 with $850 \mathrm{~g} / \mathrm{kg} \mathrm{H}_{3} \mathrm{PO}_{4}$. Flow rate was $1 \mathrm{ml} / \mathrm{min}$. The chromatogram was analysed by computer integration (model CR4A Shimadzu)

Linear calibration plots of both catecholamines were obtained in the expected ranges for plasma. Recovery rates $(62-88 \%)$ and coefficients of variation $(2.4-6.9)$ were satisfactory.

\section{Statistics}

The data are presented as means \pm SEM. Wilcoxon's ranking test was used to determine whether significant changes occurred with time within the groups. Mann-Whitney's ranking test for unpaired data was used to determine differences between diabetic and control subjects. Pearson correlation analysis was used for the assessment of correlations between different parameters. A p value of less than 0.05 was considered significant.

\section{Results}

There were no significant differences between the two groups with respect to anthropometric quantities, workload, heart rate or blood pressure (tab. 1). The electrocardiograms at rest, and during and after exercise were normal in all subjects.

Basal values of lactate, $C$-peptide, norepinephrine and epinephrine were not significantly different between the two groups. Glucose concentrations were significantly higher in the diabetics $(p<0.01$ for all values, tab. 2). $\mathrm{HbA}_{1 \mathrm{c}}$ values differed significantly between controls and diabetics: $3.2 \pm 0.5 \%$ and $8.6 \pm 0.8 \%$, respectively $(p<0.01)$. Basal insulin levels were significantly higher in the diabetics $(p<0.01)$ (tab. 2).

Blood glucose alterations during and after exercise in both groups are shown in figure 1. During exercise and up to $60 \mathrm{~min}$ into the recovery phase, there were no significant changes in blood glucose levels in the diabetic group. However, in controls, at $60 \mathrm{~min}$ into the $\forall m n m n$ $0 \infty a \underline{2}$

$+1+1+1+1$ $n ?-0.0$ 守守它令 
recovery phase, glucose was significantly higher than in mid-exercise $(p<0.05)$ (tab. 2).

Blood lactate concentrations increased markedly at the midpoint ( $7 \mathrm{~min}$ ) and at the end of exercise in both groups (for all values $\mathrm{p}<0.05$ vs. basal) (tab. 2). As shown in figure 2, values at the end of exercise were higher than the values obtained at 20 and $60 \mathrm{~min}$ of recovery in both groups $(p<0.05)$. Only in the diabetic group were midexercise lactate levels significantly higher than those after 20 min of recovery $(p<0.05)$. The basal lactate values, as well as those measured in the middle of exercise, at the end of exercise, after $20 \mathrm{~min}$ recovery and after $60 \mathrm{~min}$ recovery did not differ significantly in the control and the diabetic group (tab. 2).

During exercise and in the recovery period, there were no significant changes in the insulin levels within each group and between the two groups. The basal insulin levels of the diabetic patients were, however, significantly higher than those of the controls $(p<0.01)$ (tab. 2).
C-peptide levels did not show significant changes in response to exercise in both groups (tab. 2).

Basal norepinephrine and epinephrine values were similar in both groups (tab. 3). Exercise increased the norepinephrine and epinephrine levels $2.5-3$-fold with maximal values at the end of exercise in both groups (fig. 3 and 4). In both groups, values at the end of exercise were significantly higher $(p<0.05)$ than the basal values and those measured in mid-exercise and after $20 \mathrm{~min}$ and $60 \mathrm{~min}$ recovery. In addition, in the diabetics, mid-exercise and $20 \mathrm{~min}$ recovery values for norepinephrine, and mid-exercise epinephrine concentrations were significantly higher than basal values $(p<0.05)$. A further difference between controls and diabetics was that the norepinephrine and epinephrine values did not differ significantly between 20 and 60 min of recovery in the controls, whereas in the diabetic patients, the $20 \mathrm{~min}$ recovery values for norepinephrine and epinephrine were higher than the $60 \mathrm{~min}$ recovery levels (tab. 3).

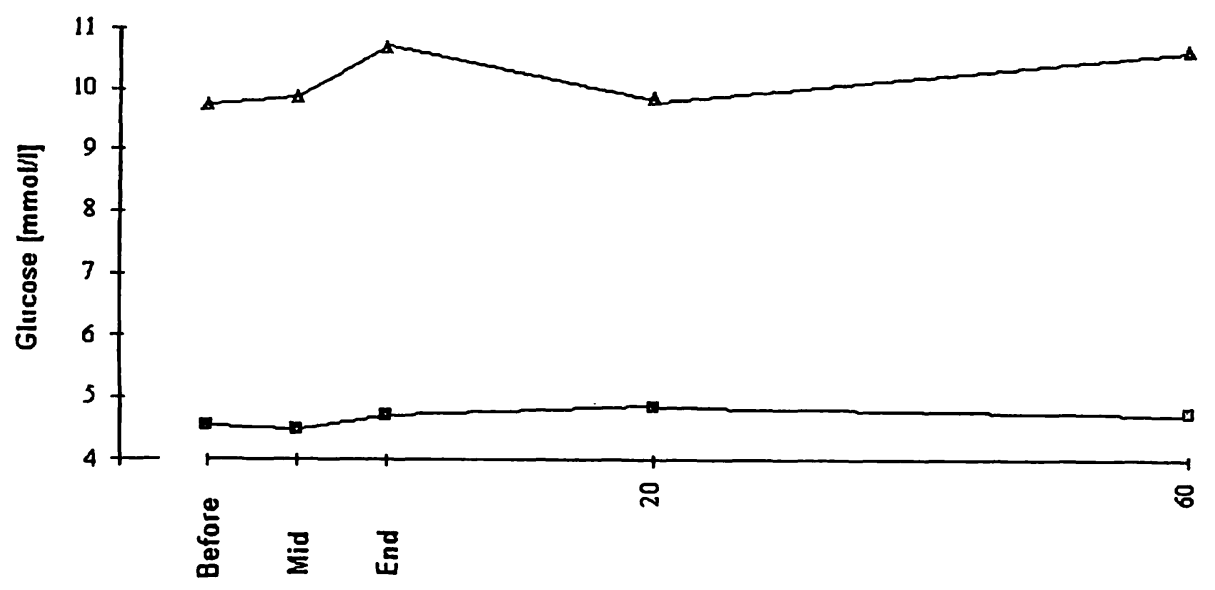

t [min]

Fig. 1 Mean plasma glucose concentrations during exercise and for $60 \mathrm{~min}$ after exercise in normal and diabetic subjects. Blood samples were drawn before exercise (Pre), at the midpoint (Mid
$7 \mathrm{~min}$ ), at the end of exercise (End, recovery 0), and after 20 and 60 minutes of recovery. Zero of the recovery time scale is at End; $\square$ denotes diabetics and $\Delta$ controls.

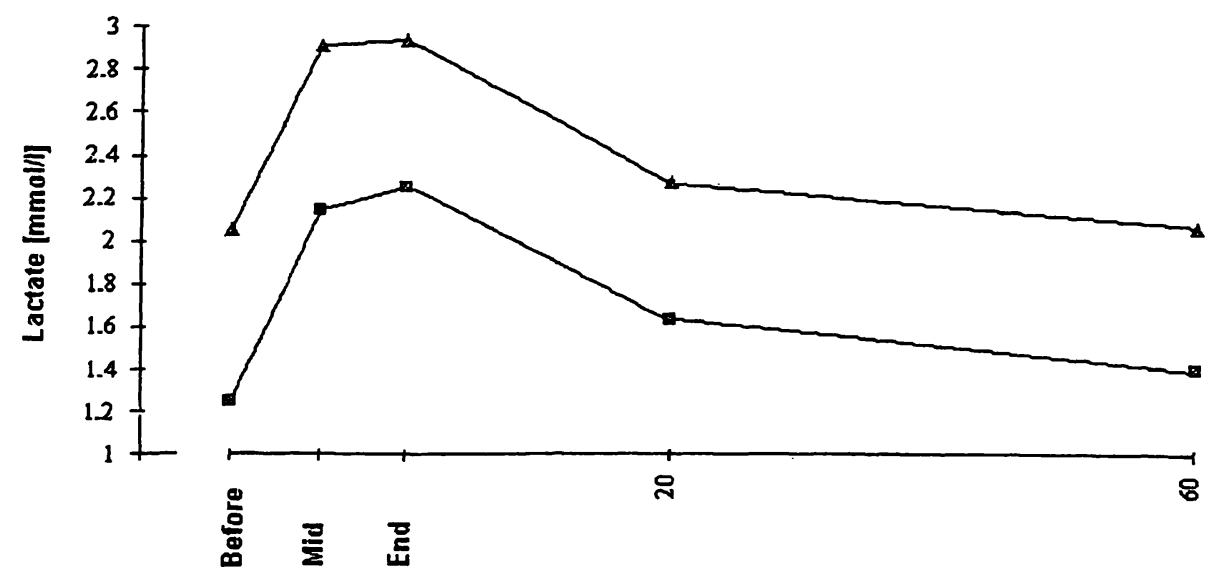

$t$ [min]

Fig. 2 Mean plasma lactate concentrations during exercise and for $60 \mathrm{~min}$ after exercise in normal and diabetic subjects. See figure 1 for key to abbreviations. 
Norepinephrine and epinephrine concentrations in responses to exercise correlated in both groups $(r=0.97$, $\mathrm{p}<0.01$ in controls and $\mathrm{r}=0.87, \mathrm{p}<0.05$ in diabetics). On the other hand, epinephrine correlated with heart rate in both groups $(r=0.82, p<0.05$ in controls and $r=0.91, p<0.01$ in the diabetic group). A strong positive correlation between epinephrine and lactate $(r=0.903, p<0.02)$ was found in diabetics but not in controls.

\section{Discussion}

In the present study, we observed that in healthy women subjects with a body mass index of $\sim 30 \mathrm{~kg} / \mathrm{m}^{2}$, after

Tab. 3 Plasma norepinephrine and epinephrine values of patients $(n=10)$ and controls $(n=10)$ at rest, mid-exercise, end-exercise (recovery 0 ), $20 \mathrm{~min}$ and $60 \mathrm{~min}$ recovery. Mean values \pm SEM are given.

\begin{tabular}{|c|c|c|c|c|}
\hline & \multicolumn{2}{|c|}{ Norepinephrine (nmol/l) } & \multicolumn{2}{|c|}{ Epinephrine (nmol/l) } \\
\hline & Diabetic & Control & Diabetic & Control \\
\hline 1. Rest (basal) & $0.357 \pm 0.044^{a, b, c}$ & $0.498 \pm 0.127^{a}$ & $0.477 \pm 0.105^{a, b}$ & $0.362 \pm 0.054$ \\
\hline 2. Mid-exercise & $0.711 \pm 0.070^{d}$ & $0.612 \pm 0.036^{b}$ & $0.740 \pm 0.113^{c, d}$ & $0.471 \pm 0.045^{b, c}$ \\
\hline 3. End-exercise & $1.501 \pm 0.107^{e, r}$ & $1.504 \pm 0.161^{c}$ & $1.028 \pm 0.0730^{e, f}$ & $0.844 \pm 0.940^{\mathrm{d}, \mathrm{e}}$ \\
\hline 4. $20 \mathrm{~min}$ recovery & $0.791 \pm 0.108^{8}$ & $0.701 \pm 0.150$ & $0.426 \pm 0.039 s$ & $0.348 \pm 0.051$ \\
\hline 5. $60 \mathrm{~min}$ recovery & $0.346 \pm 0.03$ & $0.385 \pm 0.073^{d}$ & $0.276 \pm 0.007$ & $0.241 \pm 0.037$ \\
\hline$p<0.05$ for all values & $\begin{array}{l}\text { a: I vs } 2 \\
\text { b: } 1 \text { vs } 3 \\
c: 1 \text { vs } 4 \\
\text { d: } 2 \text { vs } 3 \\
\text { e: } 3 \text { vs } 4 \\
: 3 \text { vs } 5 \\
\text { g: } 4 \text { vs }\end{array}$ & $\begin{array}{l}\text { a: } 1 \text { vs } 3 \\
\text { b: } 2 \text { vs } 3 \\
\text { c: } 3 \text { vs } 4 \\
\text { : } 3 \text { vs } 5\end{array}$ & $\begin{array}{l}\text { a: } 1 \text { vs } 2 \\
\text { b: } 1 \text { vs } 3 \\
\text { c: } 2 \text { vs } 3 \\
\text { d: } 2 \text { vs } 5 \\
\text { c: } 3 \text { vs } 4 \\
\text { : } 3 \text { vs } 5 \\
\text { b: } 4 \text { vs } 5\end{array}$ & $\begin{array}{l}\text { a: } 1 \text { vs } 3 \\
\text { b: } 2 \text { vs } 3 \\
\text { c: } 2 \text { vs } 5 \\
\text { d: } 3 \text { vs } 4 \\
\text { c: } 3 \text { vs } 5\end{array}$ \\
\hline
\end{tabular}

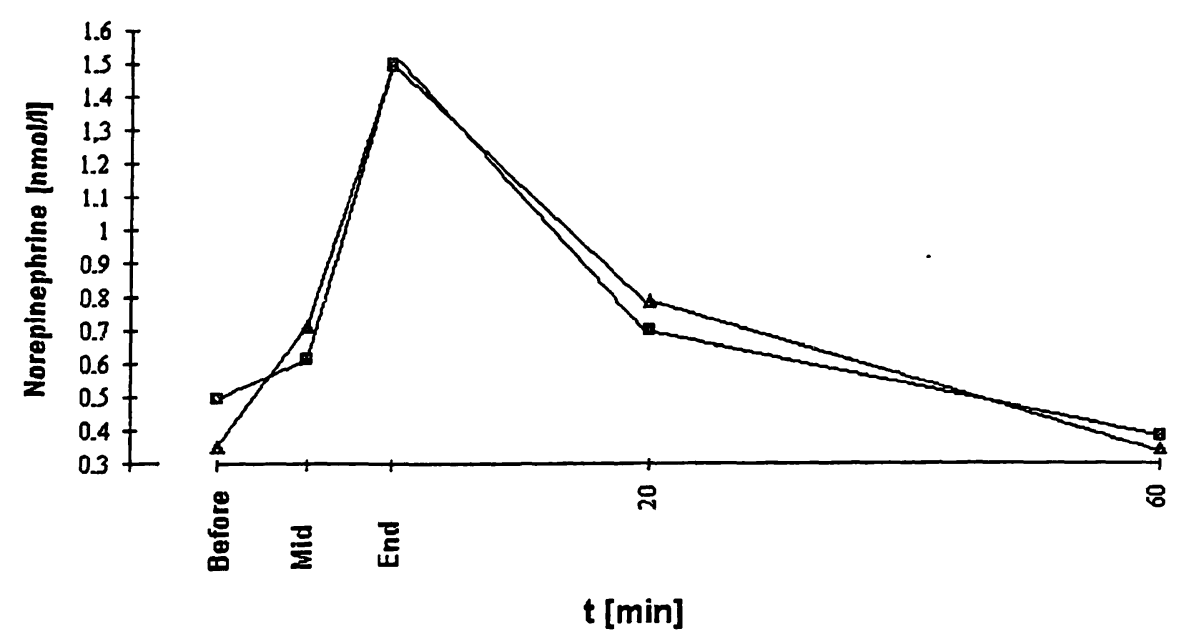

Fig. 3 Mean plasma norepinephrine concentrations during exercise and for $60 \mathrm{~min}$ after exercise in normal and diabetic subjects. See figure 1 for key to abbreviations.

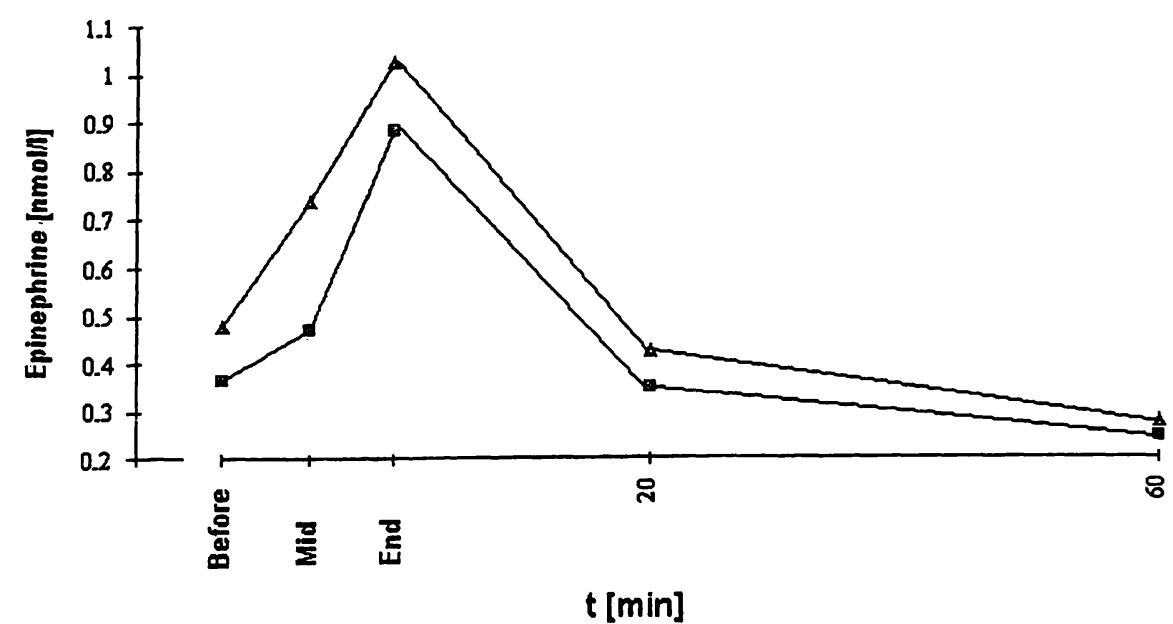

Fig. 4 Mean plasma epinephrine concentrations during exercise and for $60 \mathrm{~min}$ after exercise in normal and diabetic subjects. See figure 1 for key to abbreviations. 
moderate exercise ( $60 \%$ of maximal heart rate), blood glucose concentrations were raised at $60 \mathrm{~min}$ into the recovery period when compared with mid-exercise levels $(p<0.05)$ and with resting levels, though the latter increase was not significant. In body mass indexmatched diabetic patients the rise in blood glucose in the corresponding period was not significant. From studies in healthy individuals it appears that the blood glucose concentration does not remain stable during prolonged exercise at $\sim 50-60 \% \mathrm{VO}_{2 \max }$ or during intense exercise, where hepatic glucose production is increased more than is necessary to compensate for peripheral glucose utilization (5). Following moderate exercise, Martin et al. observed an increase in blood glucose concentration in healthy controls while the opposite was true in noninsulin-dependent diabetic patients exercising at the same work intensity (1). Our findings in non-insulindependent diabetics do not confirm these observations. This discrepancy might be due to differences in the catecholamine responses between the two studies. They observed similar norepinephrine and epinephrine responses in controls and in diabetics, while our findings showed that though basal catecholamine values were similar in both groups, non-insulin-dependent diabetic patients exhibited an earlier (basal vs mid-exercise; $p<0.05$ in diabetics, not significant in controls) and prolonged (basal vs recovery 20 and recovery 20 vs recovery 60 both $\mathrm{p}<0.05$ in diabetics) catecholamine response, compared with controls. Catecholamines exert potent effects on glucose metabolism by stimulating lipolysis in adipose tissue, thus inhibiting excessive glucose consumption (1). They contribute to a great extent to the maintenance of euglycaemia during and after exercise. In the light of the results of previous studies we propose that catecholamines are mainly responsible for the prevention of exercise-induced hypoglycaemia in both controls and diabetics in the present study, where insulin and C-peptide concentrations did not change $(1,16)$. An-

\section{References}

1. Martin IK, Wahren J. Glucose metabolism during physical exercise in patients with noninsulin-dependent (type II) diabetes. Adv Exp Med Biol 1993; 334:221-33.

2. American Diabetes Association. Position statement: diabetes mellitus and exercise. Diabetes Care 1990 a; 13:84.

3. American Diabetes Association. Technical review; exercise and NIDDM. Diabetes Care 1990 b. 13:785-9.

4. Hough DO. Diabetes mellitus in sports. Med Clin North Am 1994; 78 (2):423-37.

5. Richter EA, Turcotte L, Hespel P, Kiens B. Metabolic responses to exercise. Diabetes Care 1992; 15 (11):1767-76.

6. Smith U, Attvall S, Eriksson J, Fowelin J. The insulin-antagonistic effect of the counterregulatory hormones - clinical and mechanistic aspects. Adv Exp Med Biol 1993; 334:169-80.

7. Houwing H, Frankel KM, Strubbe JH, Suylichem PT, Steffens $\mathrm{AB}$. Role of the sympathoadrenal system in exercise-induced inhibition of insulin secretion. Diabetes 1995; 44:565-71.

8. Podolin DA, Munger PA, Mazzeo RS. Plasma catecholamine and lactate response during graded exercise with varied glycogen conditions. J Appl Physiol 1991; 71 (4):1427-33. other possible explanation for the prevention of hypoglycaemia in this condition with no significant decrements in insulin and $\mathrm{C}$-peptide concentrations may be that catecholamines stimulate hepatic glucose production via glycogenolysis but have no significant effect on glucose clearance $(1,16,17)$.

Lactate, which accumulates as a result of enhanced glycogenolysis stimulated by catecholamines, did not differ between controls and diabetics at rest; it increased in a similar manner in both groups, reaching maximal values at the end of exercise and returned to resting values in the $60 \mathrm{~min}$ of recovery. These findings are in accordance with those of others (13). We observed a significant positive correlation between lactate and epinephrine values in non-insulin-dependent diabetic patients $(r=0.903$, $\mathrm{p}<0.02$ ). Podolin et al. found a similar correlation in their exercising subjects and reported a causal relationship between lactate and epinephrine during exercise (8).

The duration and intensity (14 $\mathrm{min}, 60 \%$ of maximal heart rate) of exercise that was performed in this study caused an earlier and prolonged increment in catecholamines in the non-insulin-dependent diabetic group, compared with the controls, and an increment in blood glucose in both groups (though not significant in diabetics) compared with the resting values. This suggests that, especially in sedentary non-insulin-dependent diabetic patients, the duration and intensity of exercise should be lower than that performed in this study, in order to benefit glucoregulation. Extension of the study by monitoring the biochemical quantities after several weeks of lower intensity exercise would be worthwhile. Nevertheless, non-insulin-dependent diabetic patients with good metabolic control do not seem to exhibit worse glucoregulatory responses to exercise than controls with similar body mass indices and levels of fitness.

9. Mazzeo RS. Catecholamine responses to acute and chronic exercise. Med Sci Sports Exerc 1991; 23 (7):839-45.

10. Purdon C, Brousson M, Nyveen L, Miles PD. The roles of insulin and catecholamines in the glucoregulatory response during intense exercise and early recovery in insulin-dependent diabetic and control subjects. J Clin Endocrinol Metab 1993; 76:566-73.

11. Johansson BL, Berg U, Bohlin AB, Lefvert AK. Feyschuss V. Exercise-induced changes in renal function and their relation to plasma noradrenaline in insulin-dependent diabetic children and adolescents. Clin Sci 1987; 72:611-20.

12. Yaşrar SA, Tulassy T, Madacsy L, Korner A, Szucs L. Sympathetic-adrenergic activity and acid-base regulation under acute physical stress in type I (insulin-dependent) diabetic children. Horm Res 1994; 42:110-5.

13. Kjaer M, Hollenbeck CB, Hewitt F, Galbao H. Glucoregulation and hormonal responses to maximal exercise in noninsulin-dependent diabetes. J Appl Physiol 1990; 68 (5):2067-74.

14. Ganhao MF, Hattingh J, Hurwitz ML, Pitts iNI. Evaluation of a simple plasma catecholamine extraction procedure prior to 
HPLC and electrochemical detection. J Chromatogr 1991; 564:55-66.

15. Foti A, Kimura S, De Quattro V, Oee D. Liquid chromatographic measurement of catecholamines and metabolites in plasma and urine. Clin Chem 1987; 33 (12):2209-13.

16. Marker JC, Hirsch IB, Smith LJ, Parvin CA. Catecholamines in prevention of hypoglycemia during exercise in humans. Endocrinol Metab 1991; 23:E705-12.

17. Golstein RE, Abumrad N, Lacy DB, Wasserman DH, Cherrington $A D$. Effects of an acute increase in epinephrine and cortisol on carbohydrate metabolism during insulin deficiency. Diabetes 1995; 44:672-81.

Received February 21/May 27, 1996

Corresponding author: Dr. Nevbahar Turgan, Department of Clinical Biochemistry, Ege University Medical School, TR-35100 Bornova, Izmir, Turkey 
